\title{
A Formal Total Synthesis of (-)-FR901483 Using a Tandem Cationic aza-Cope Rearrangement/Mannich Cyclization Approach
}

\author{
Kay M. Brummond and Sang-phyo Hong \\ Department of Chemistry, University of Pittsburgh, Pittsburgh, PA 15260
}

Supporting Information

$\begin{array}{lc}{ }^{1} \mathrm{H} \text { NMR and }{ }^{13} \mathrm{C} \text { NMR spectra } & \mathrm{S} 2-\mathrm{S} 24 \\ \text { Crystal structures of compound } \mathbf{1 1} \text { and } \mathbf{2 9} \text { (isomer 1) } & \mathrm{S} 25\end{array}$ 
${ }^{1} \mathrm{H}$ and ${ }^{13} \mathrm{C}$ NMR spectra

Compound 11

品

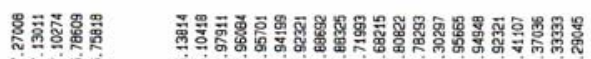

सTि"

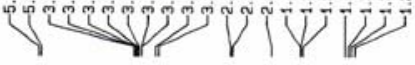

MeOCOC
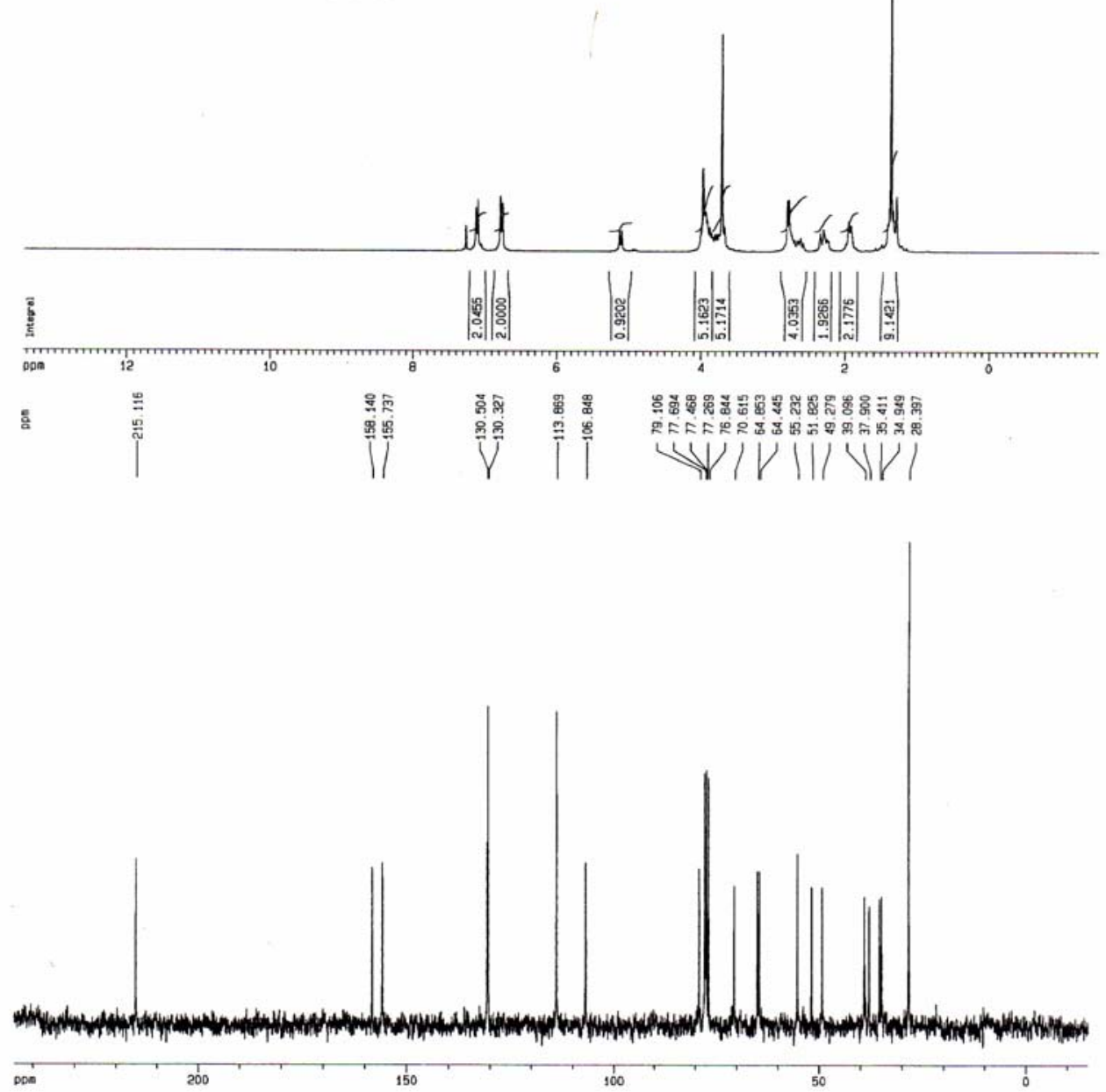


\section{Compound 14}

要<smiles>COc1ccc(C[C@H](NC(=O)OCc2ccccc2)[C@H](O)[C@@H]2CC3(CC[C@@H]2O)OCCO3)cc1</smiles>

:

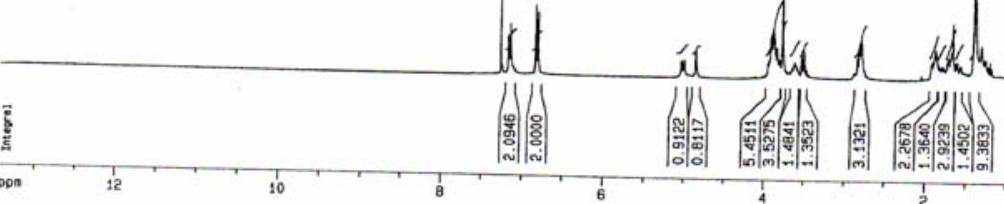

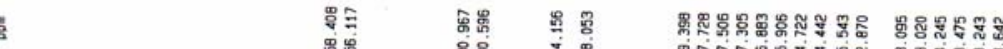

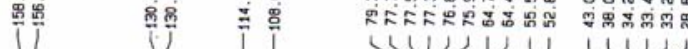

$V$ i W WIINW

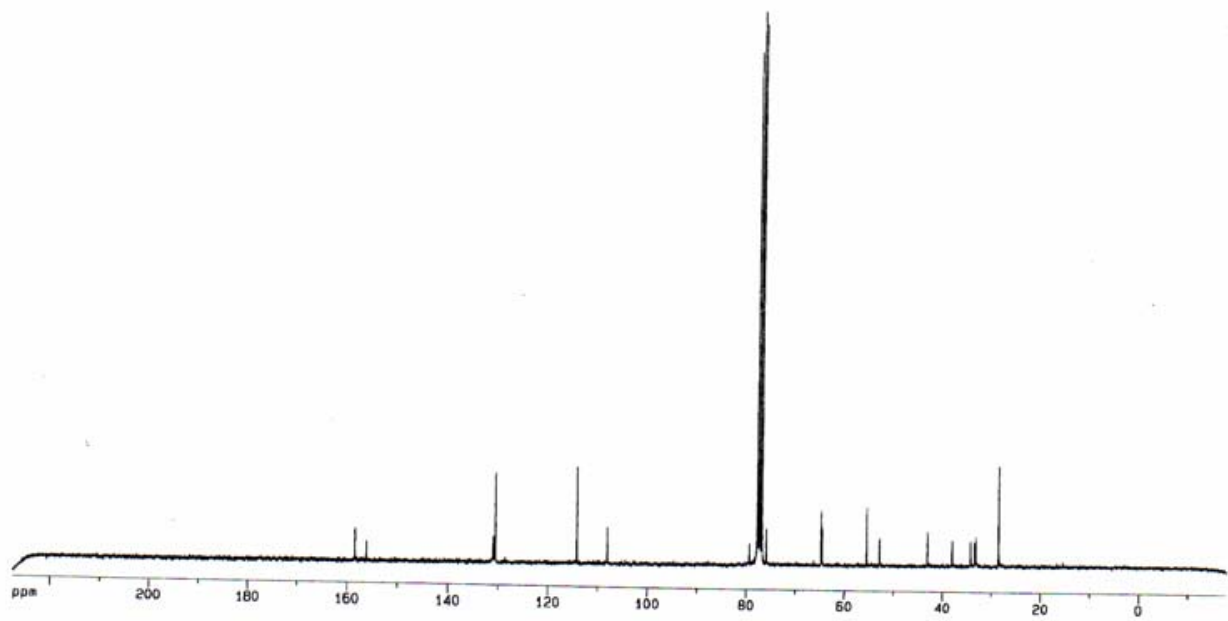




\section{Compound 16}<smiles>COc1ccc(C[C@H](NC(=O)OCc2ccccc2)C(OCc2ccccc2)C2CC3(CCC2CC(C)(C)C)OCCO3)cc1</smiles>
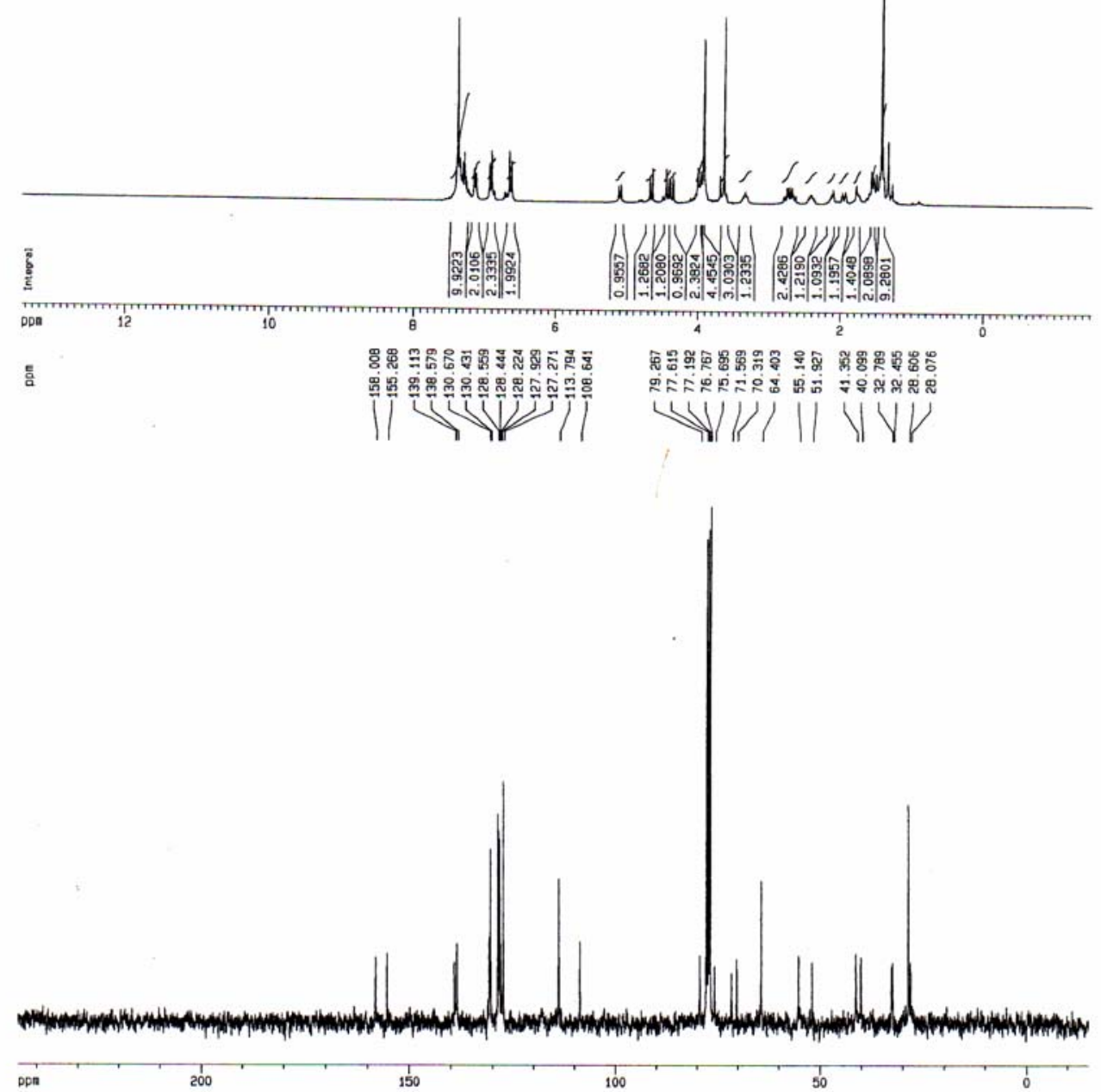


\section{Compound 18}
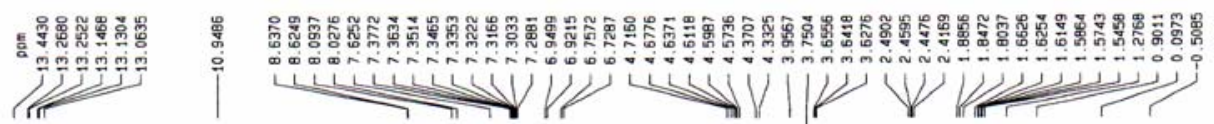

(c)
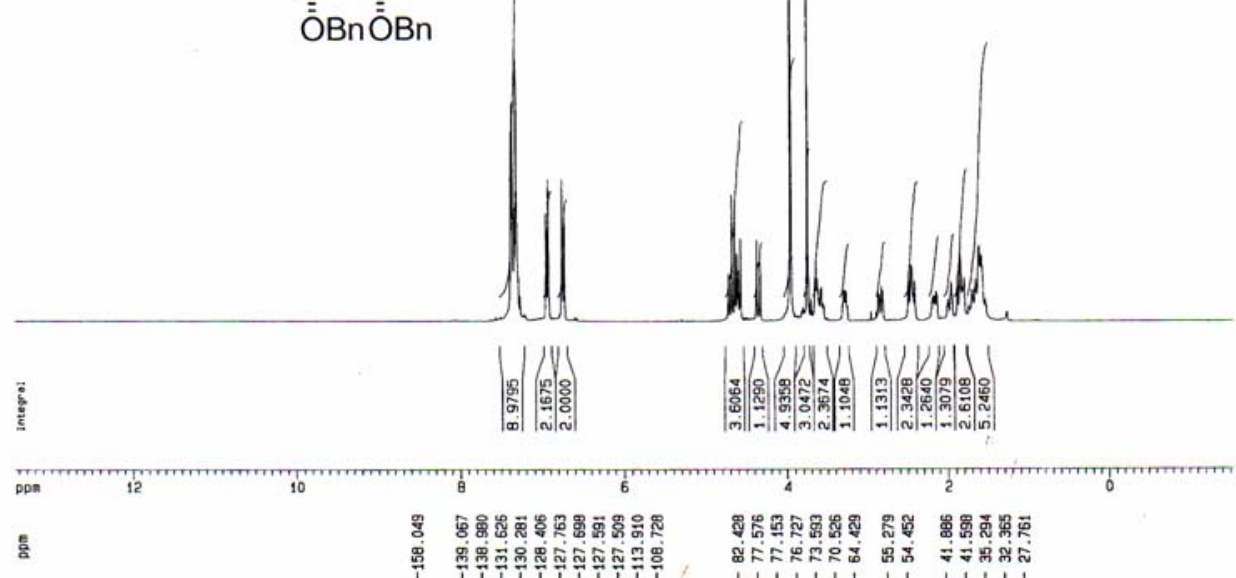

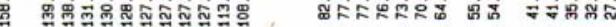
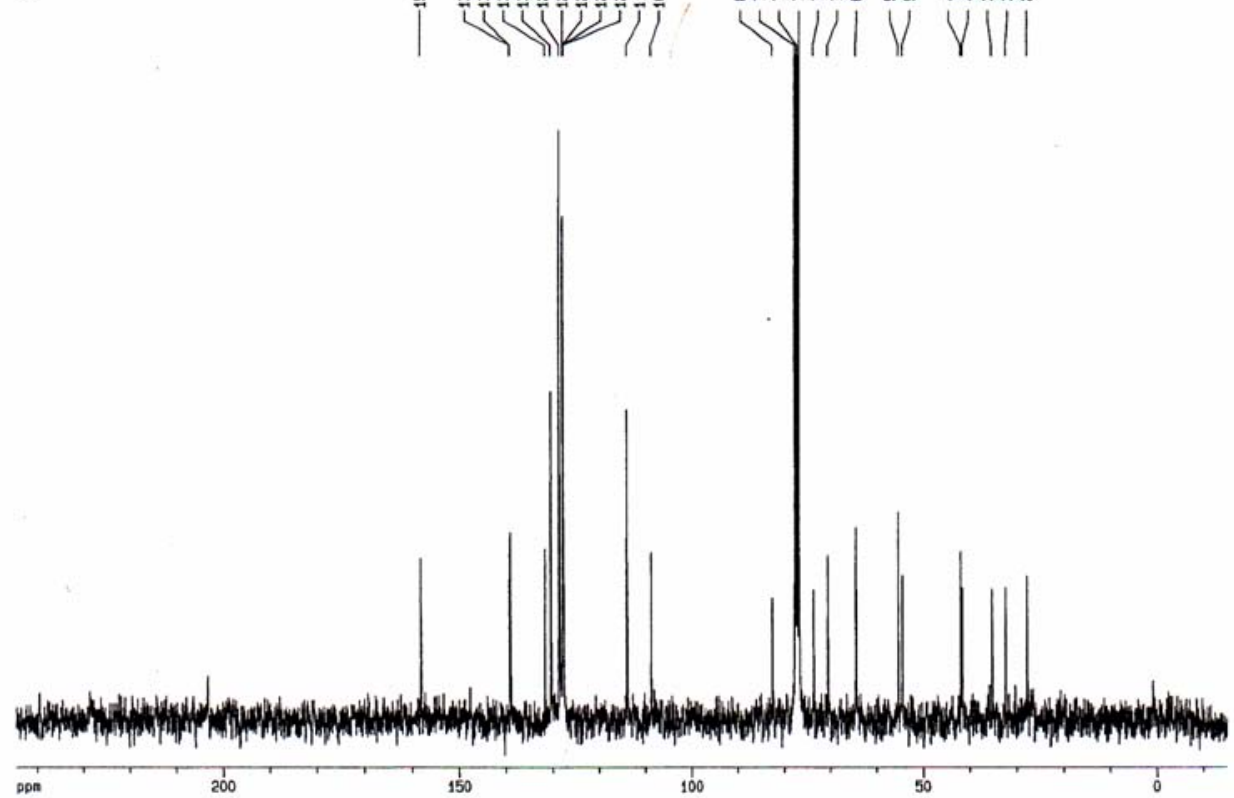
Compound 22 (isomer 1)

咅

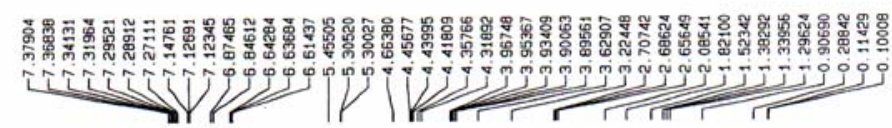<smiles>C=CC(O)C(=O)N[C@H](Cc1ccc(OC)cc1)C(OCc1ccccc1)C1CC2(CCC1Cc1ccccc1)OCCO2</smiles>

Isomer 1
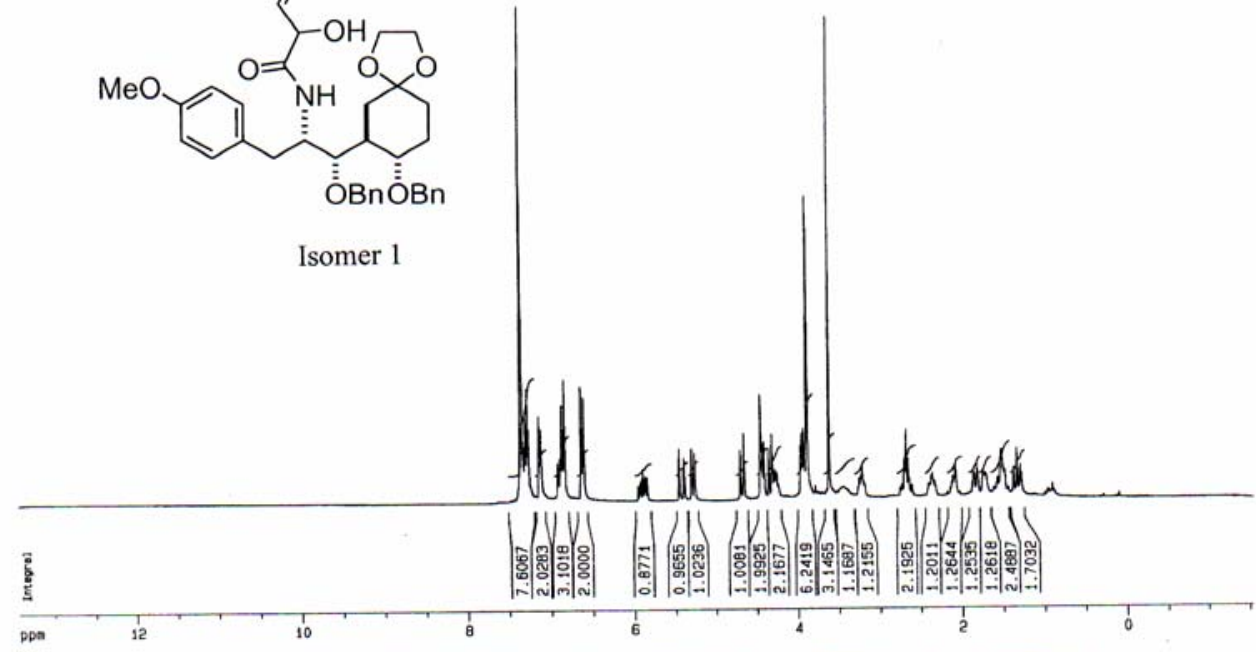

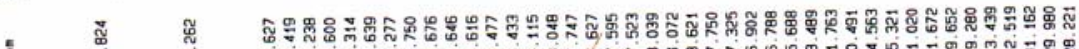

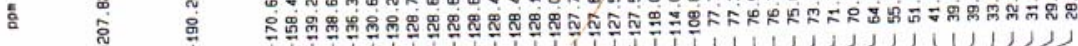

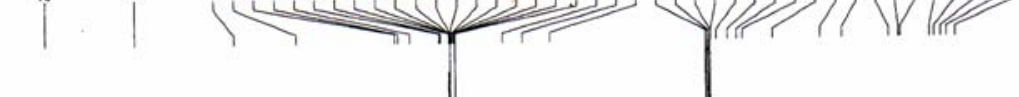

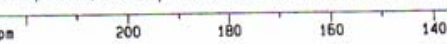

120

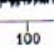


Compound 22 (isomer 2)
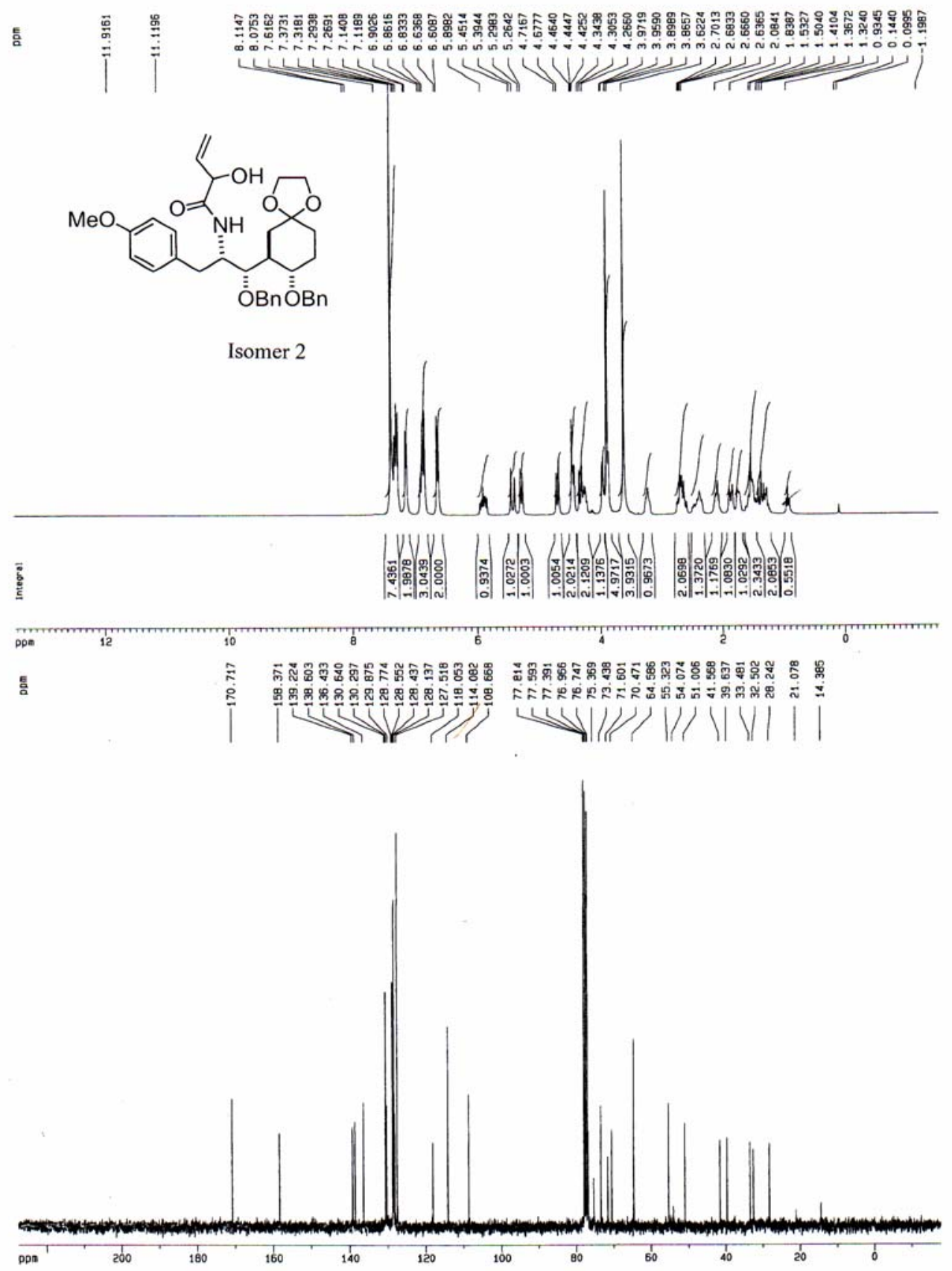
Compound 26 (isomer 1)

吾

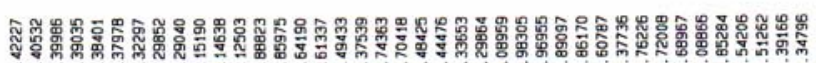

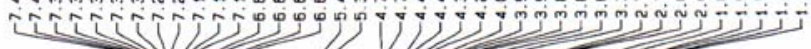

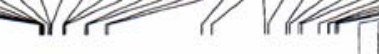<smiles>C=CC(OC)C(=O)N[C@H](Cc1ccc(OC)cc1)C(O)C1CC2(OCC)CCC1[C@H](Cc1ccccc1)OCCO2</smiles>

Isomer 1
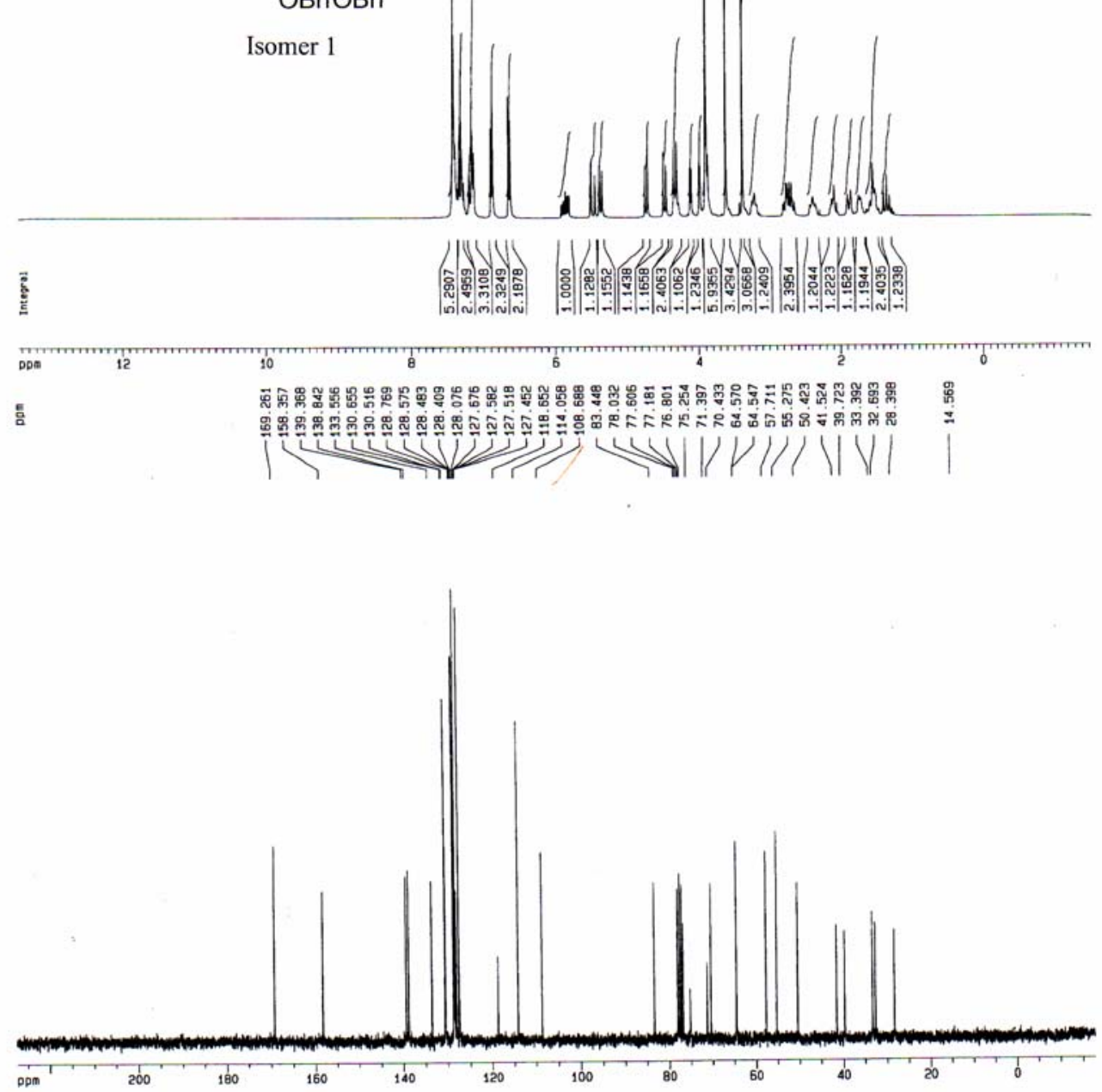
Compound 26 (isomer 2)

骨

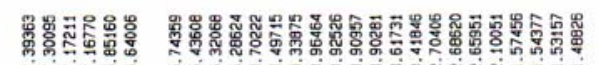

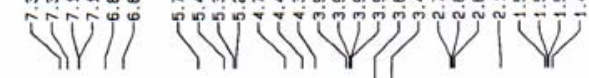

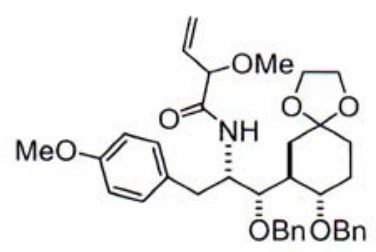

Isomer 2
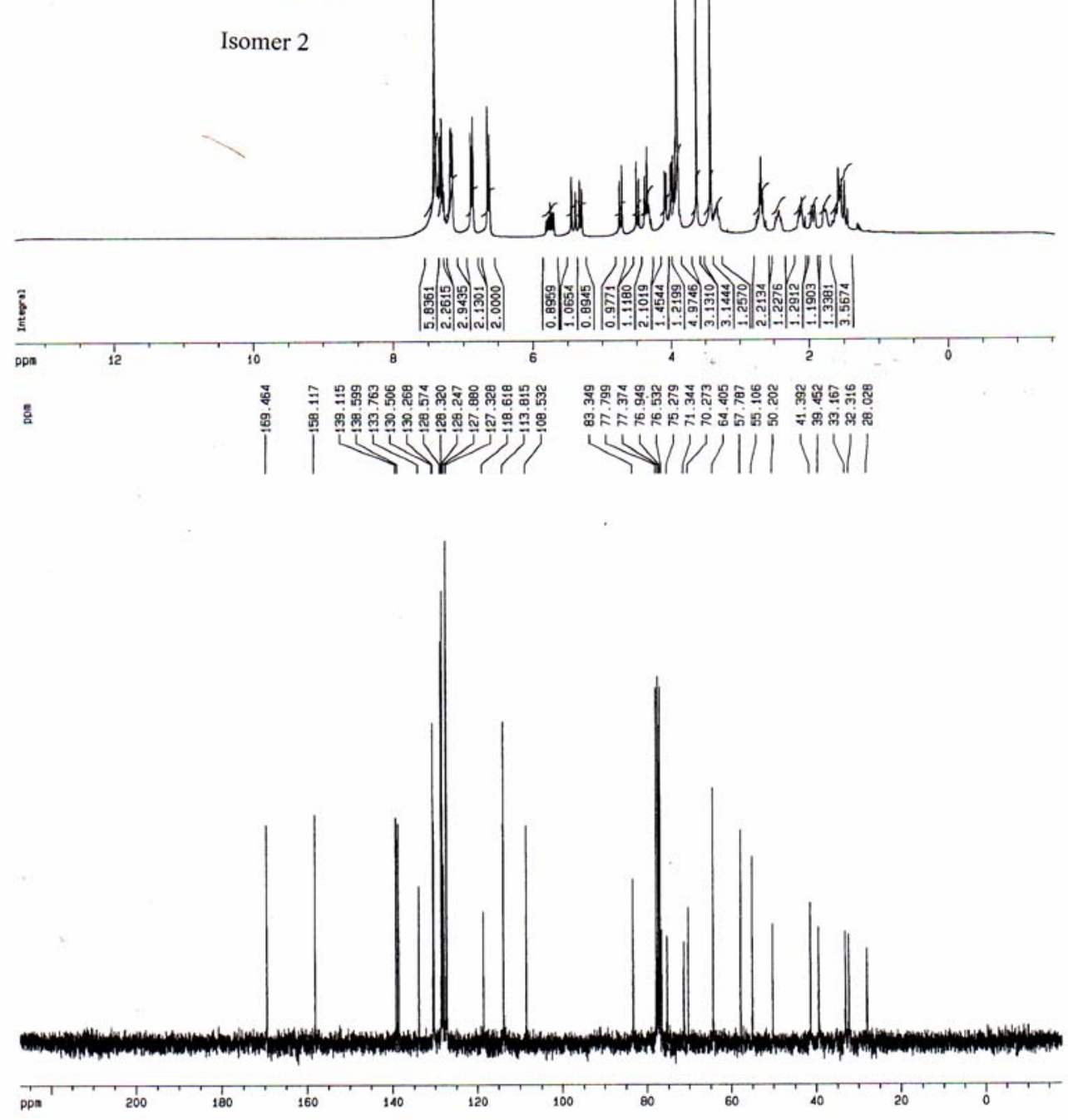
Compound 27 (isomer 1)

s
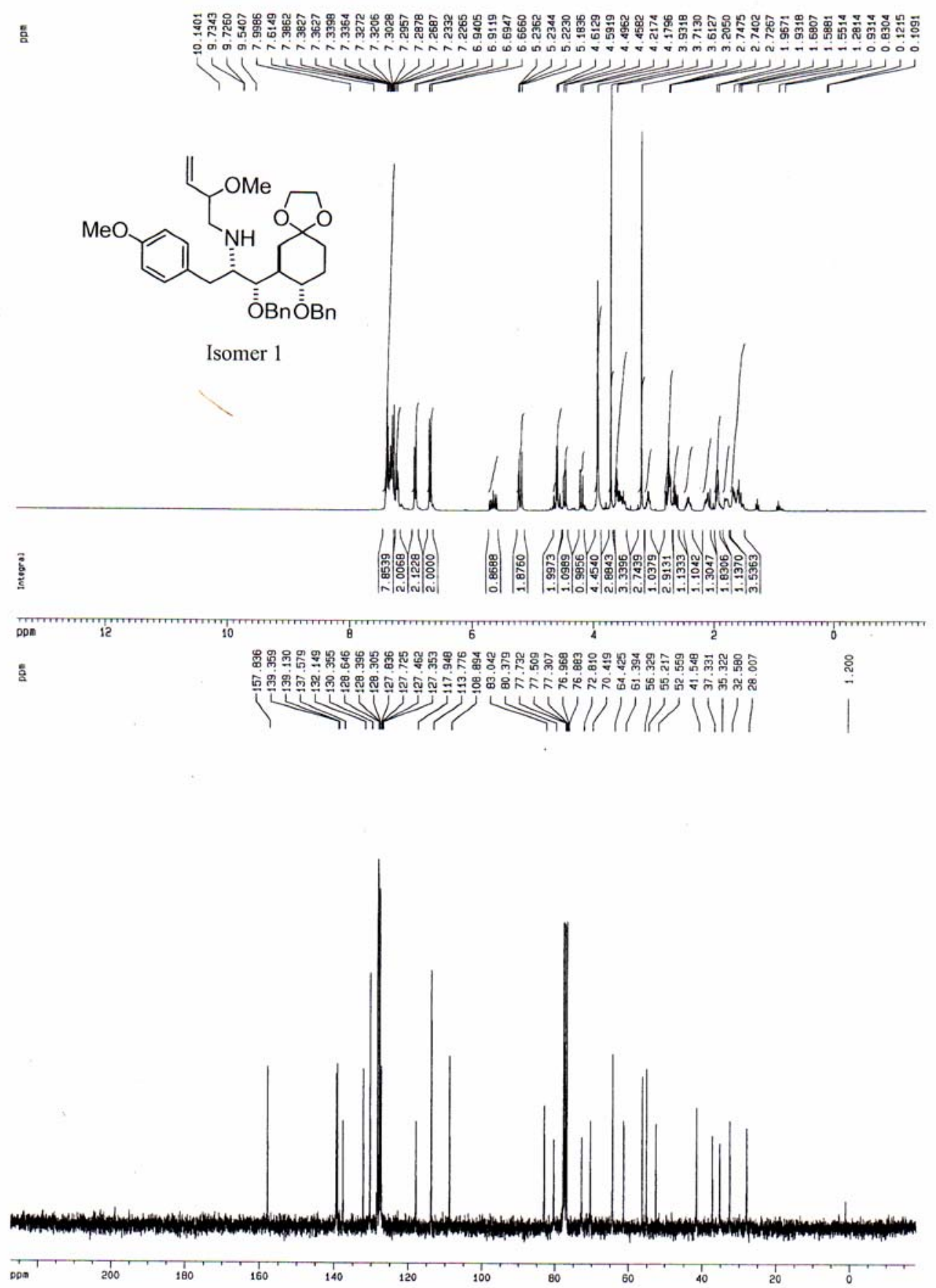
Compound 27 (isomer 2)
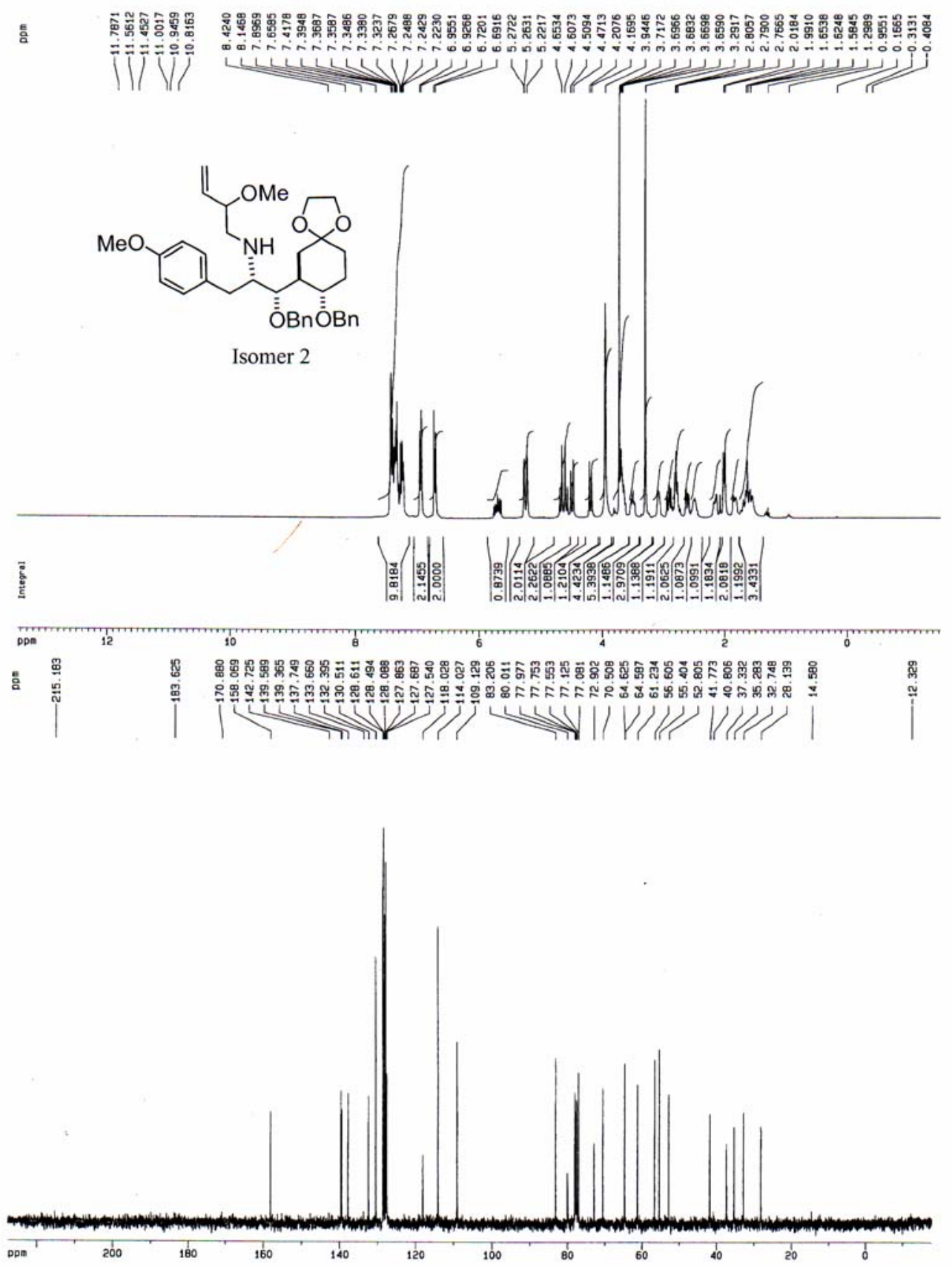
Compound 28 (isomer 1)

ลั

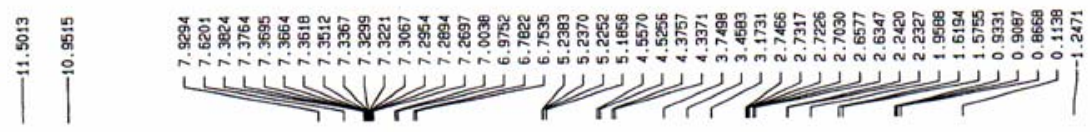<smiles>C=CC(CN[C@@H](Cc1ccc(OC)cc1)[C@H](OCc1ccccc1)C1CC(=O)CC[C@H]1Cc1ccccc1)OC</smiles>

Isomer 1

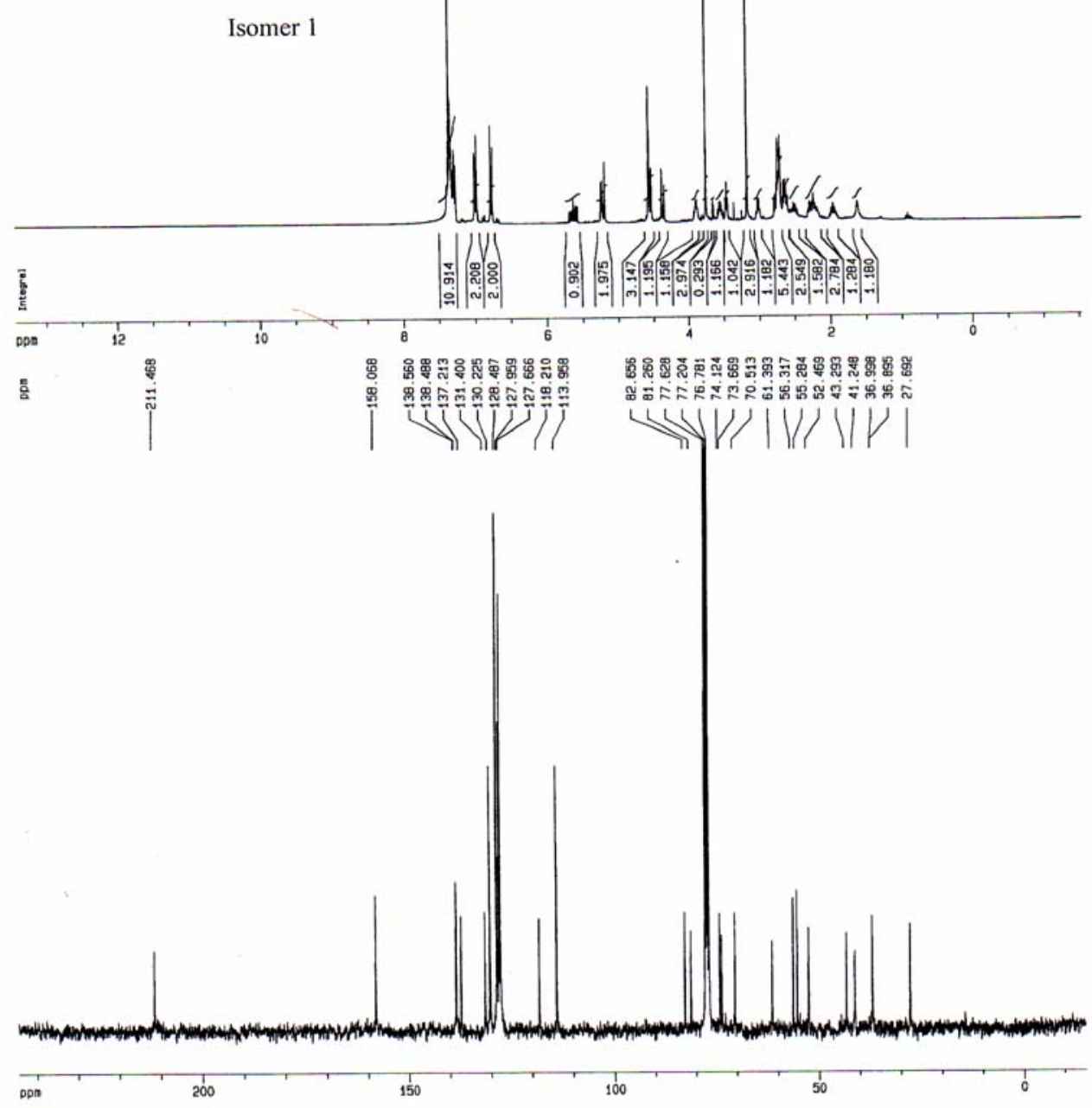


Compound 28 (isomer 2)

要

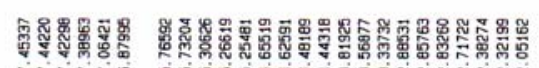
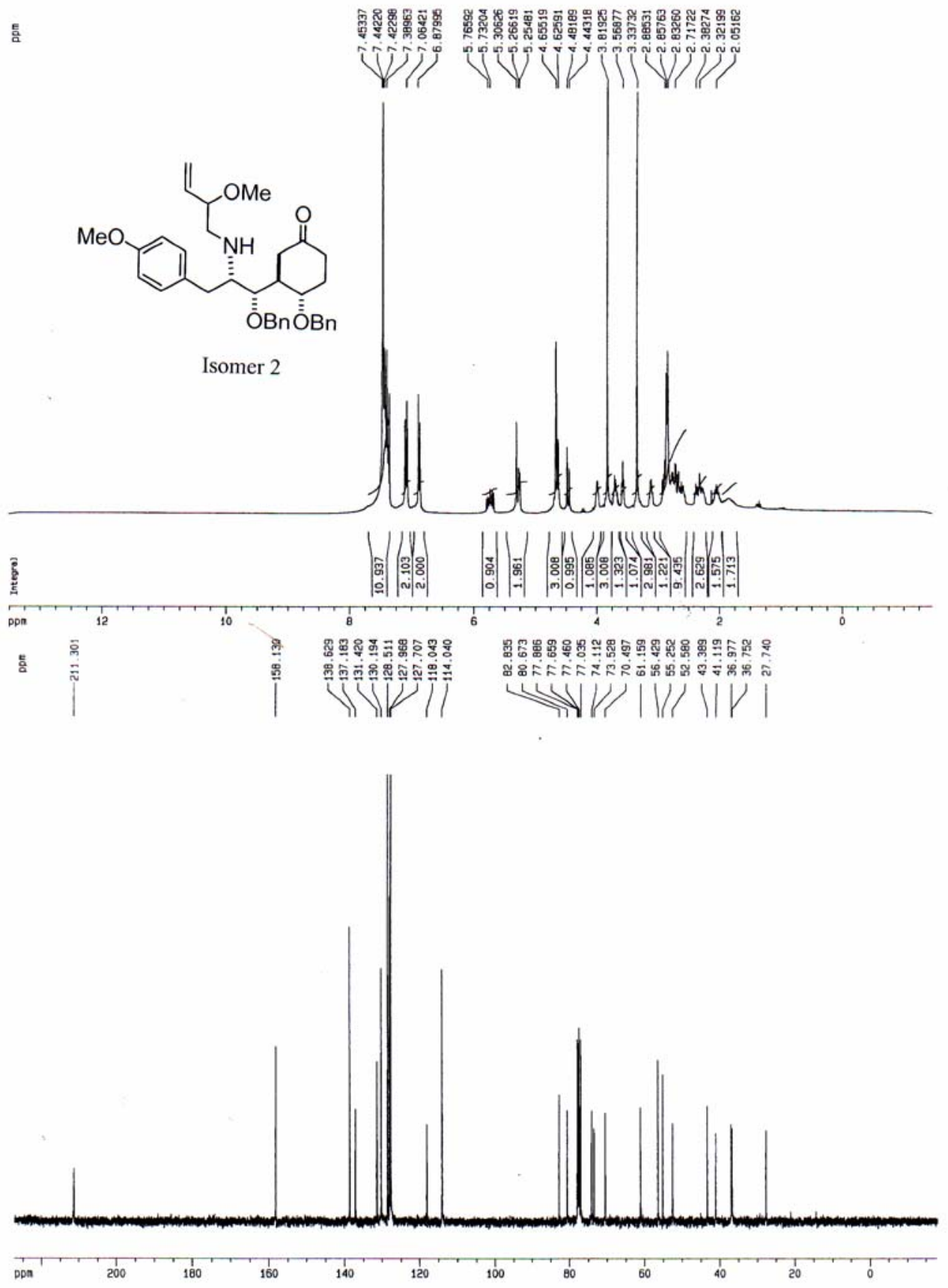
Compound 29 $\alpha$
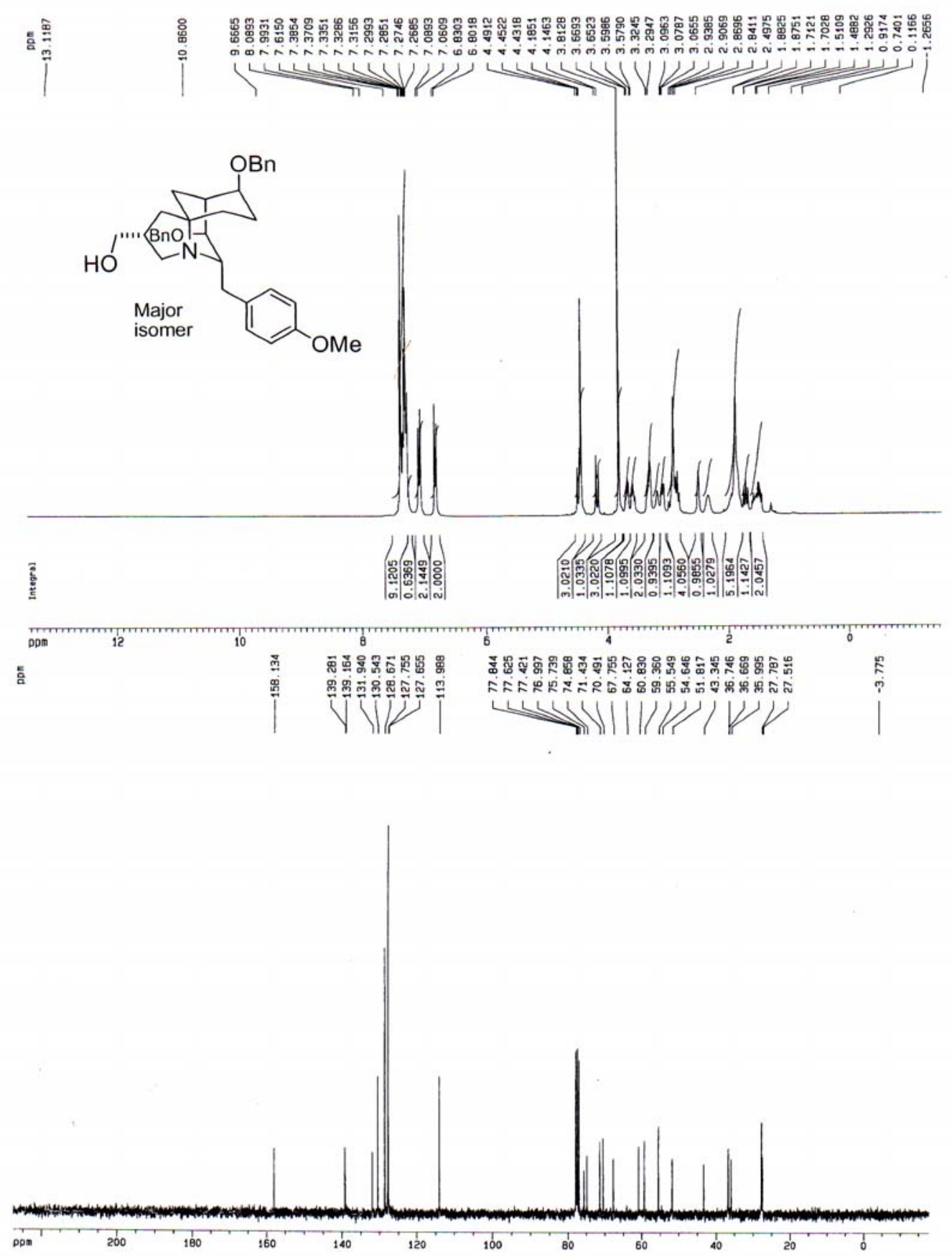
Compound $29 \alpha\left({ }^{1} \mathrm{H}-{ }^{1} \mathrm{H}\right.$ COSY, DEPT $)$
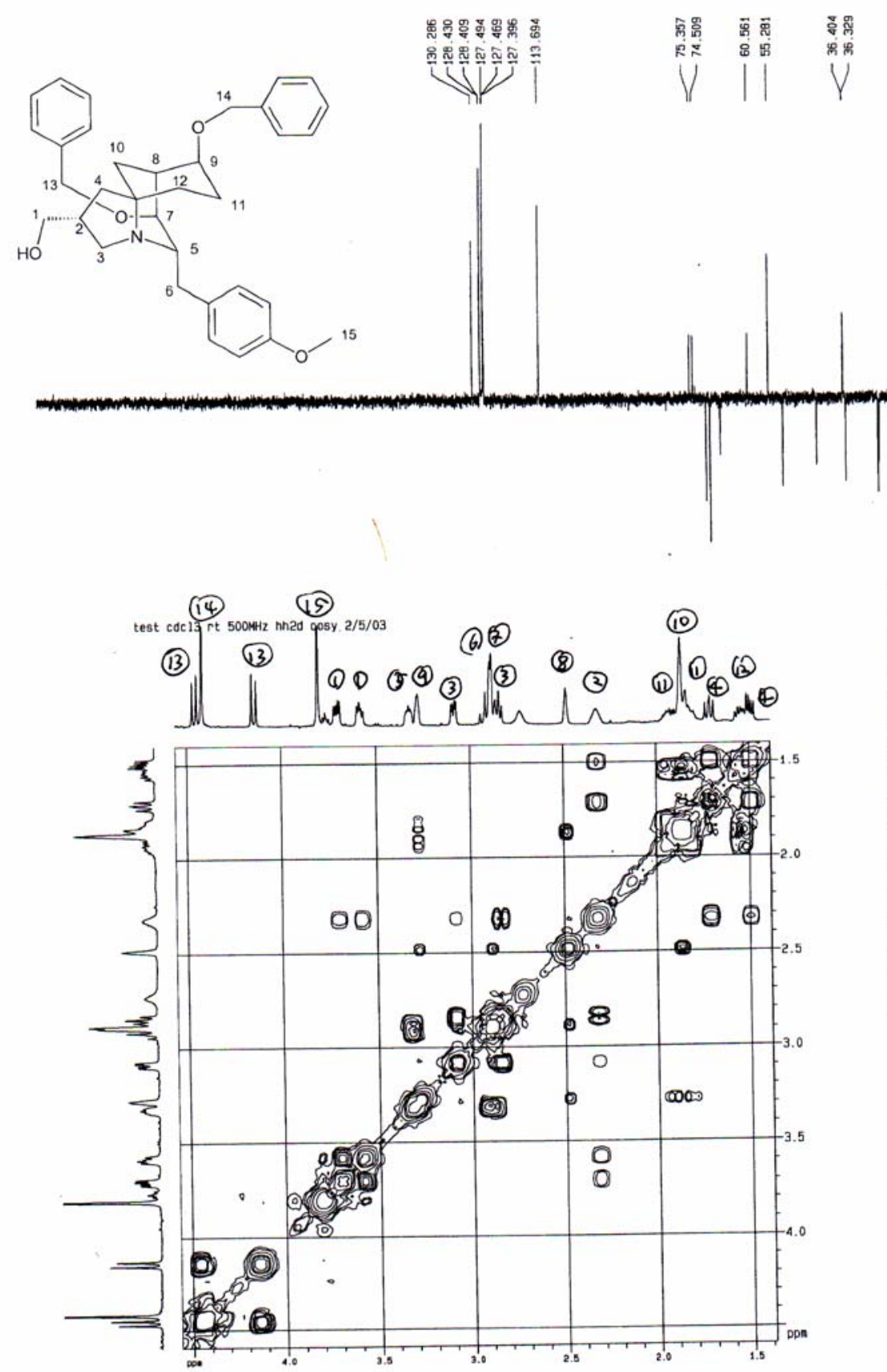

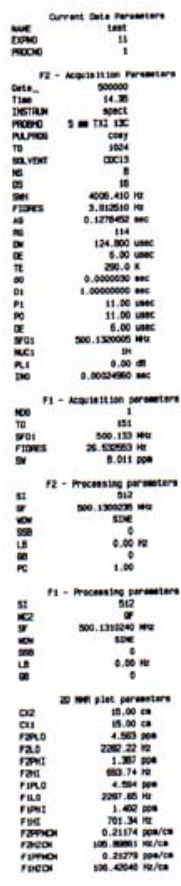


Compound 29 $\alpha$ (NOE)

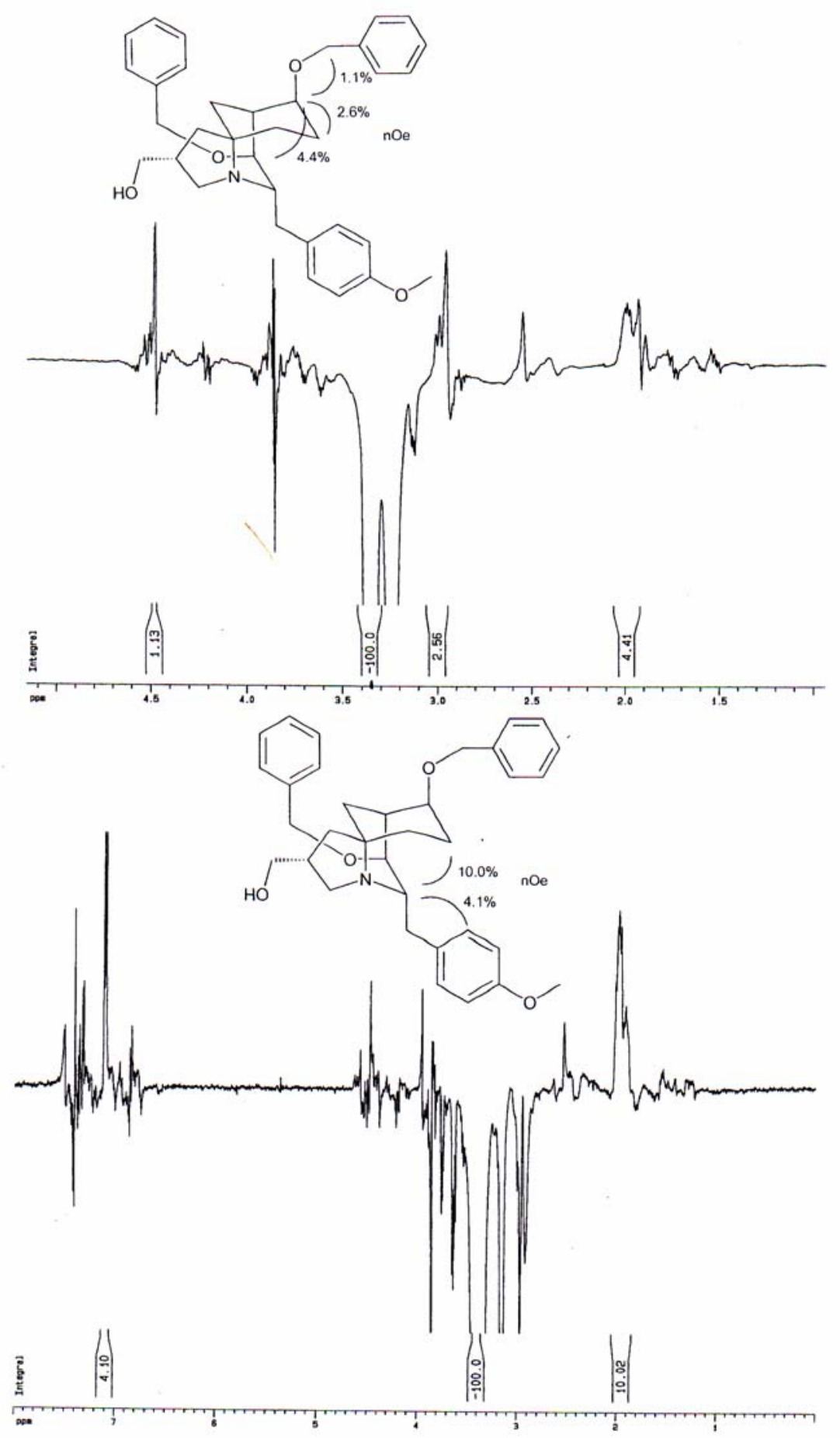


Compound $29 \beta$

镸

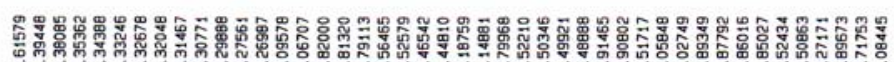

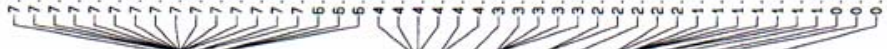

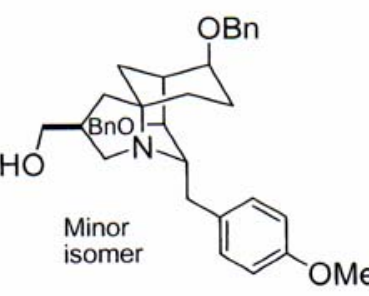

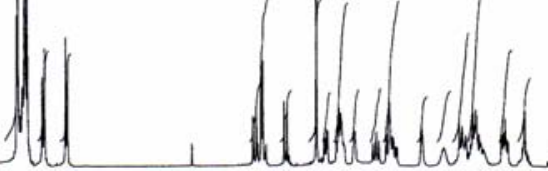

1

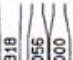

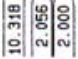

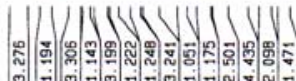

pon

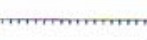

a

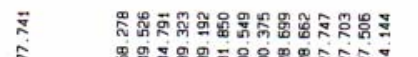

ก

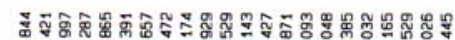

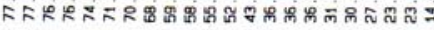

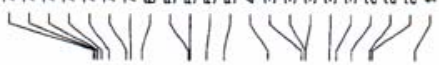

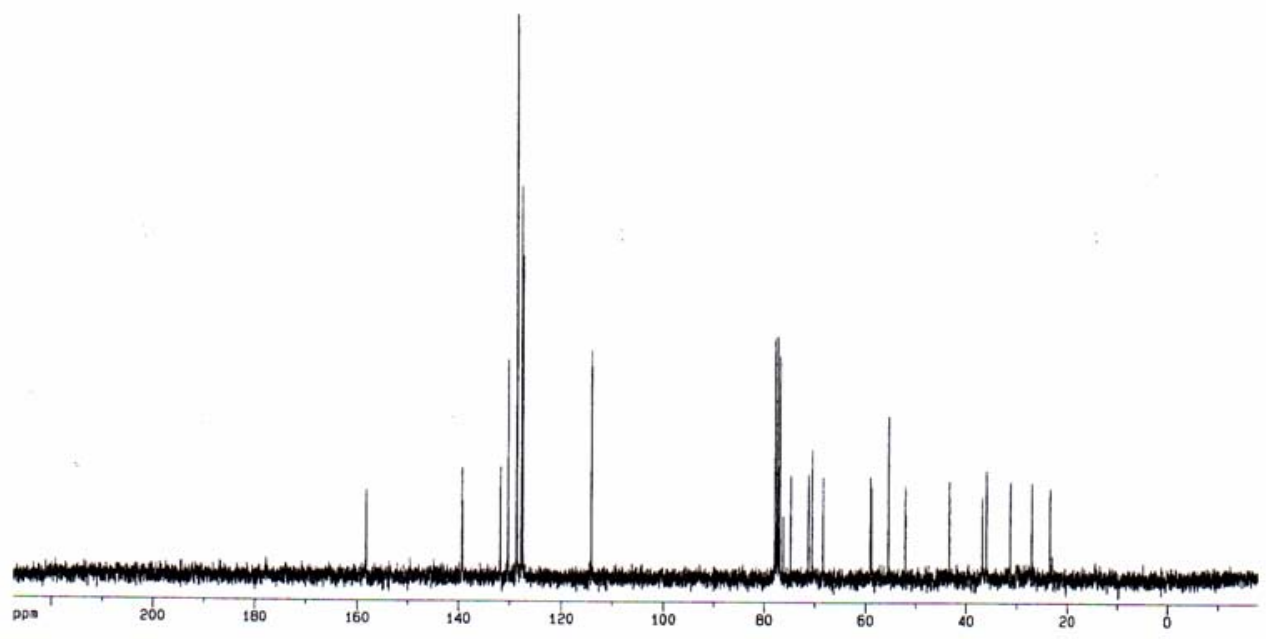


Compound $34 \beta$
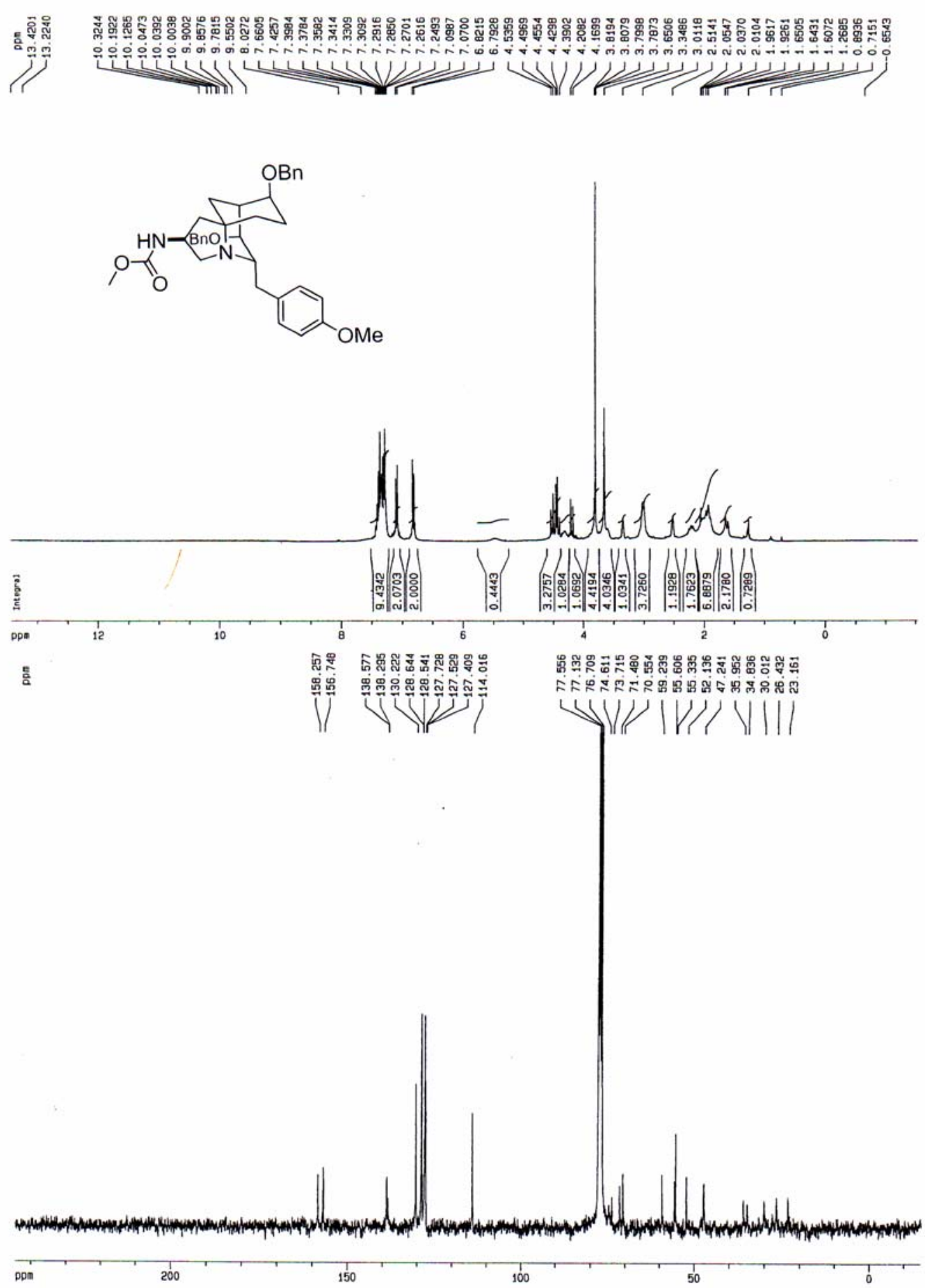
Compound $32 \beta$

ล

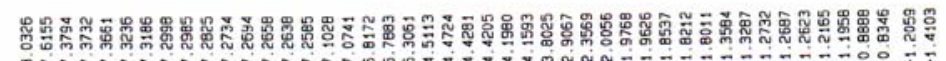
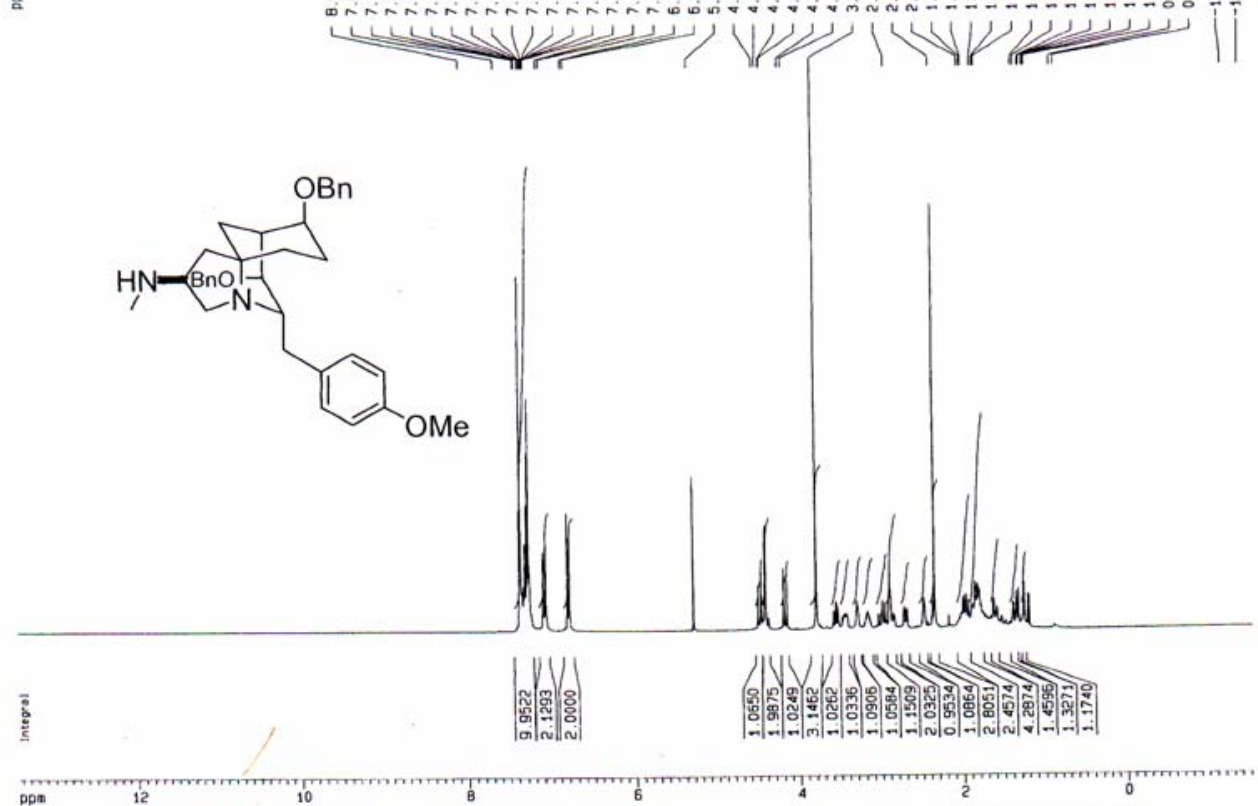

pon

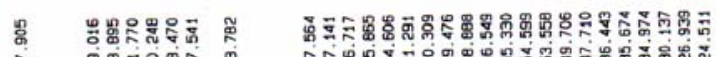

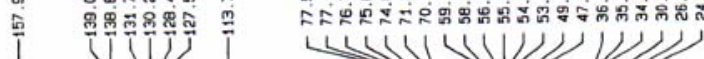

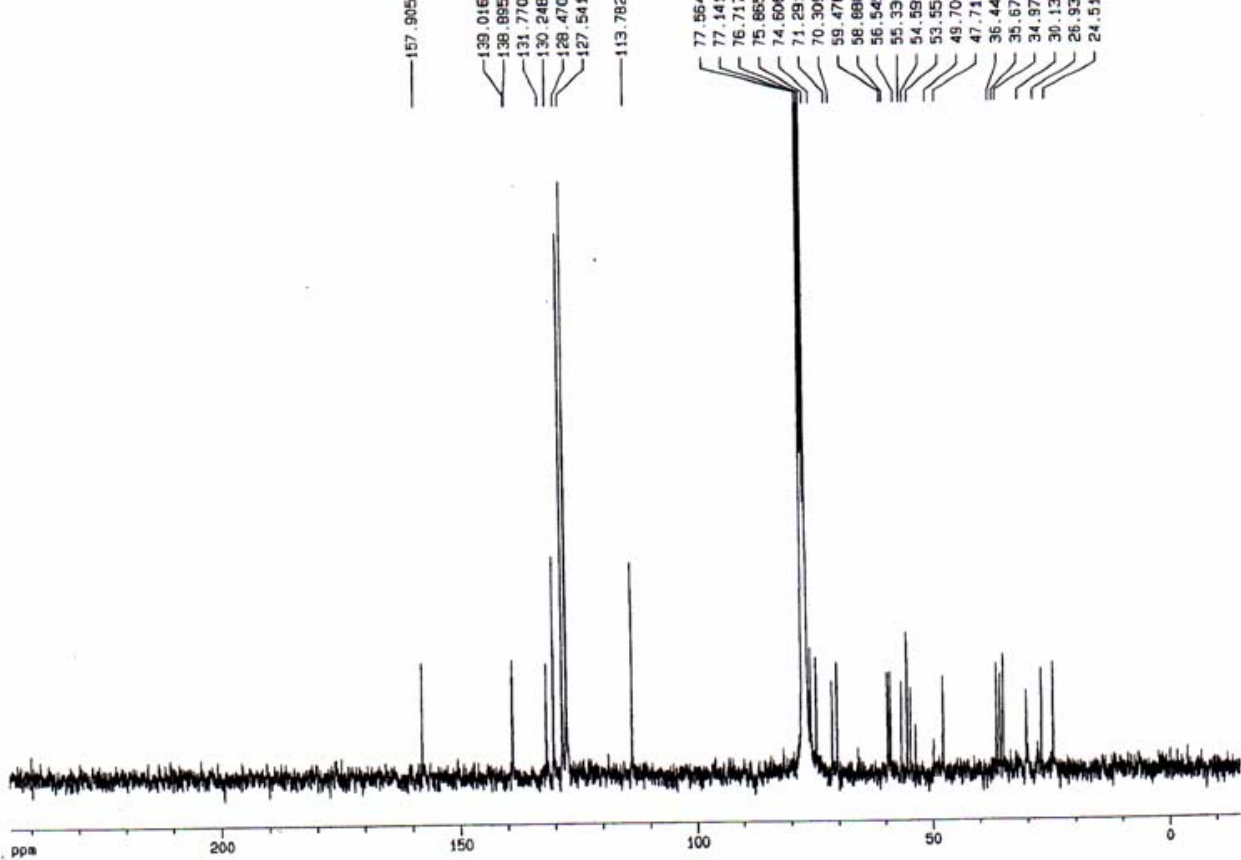


[7,9-Bis-benzyloxy-6-(4-methoxybenzyl)-5-aza-tricyclo[6.3.1.01,5]dodec-3-yl]methylcarbamic acid tert-butyl ester

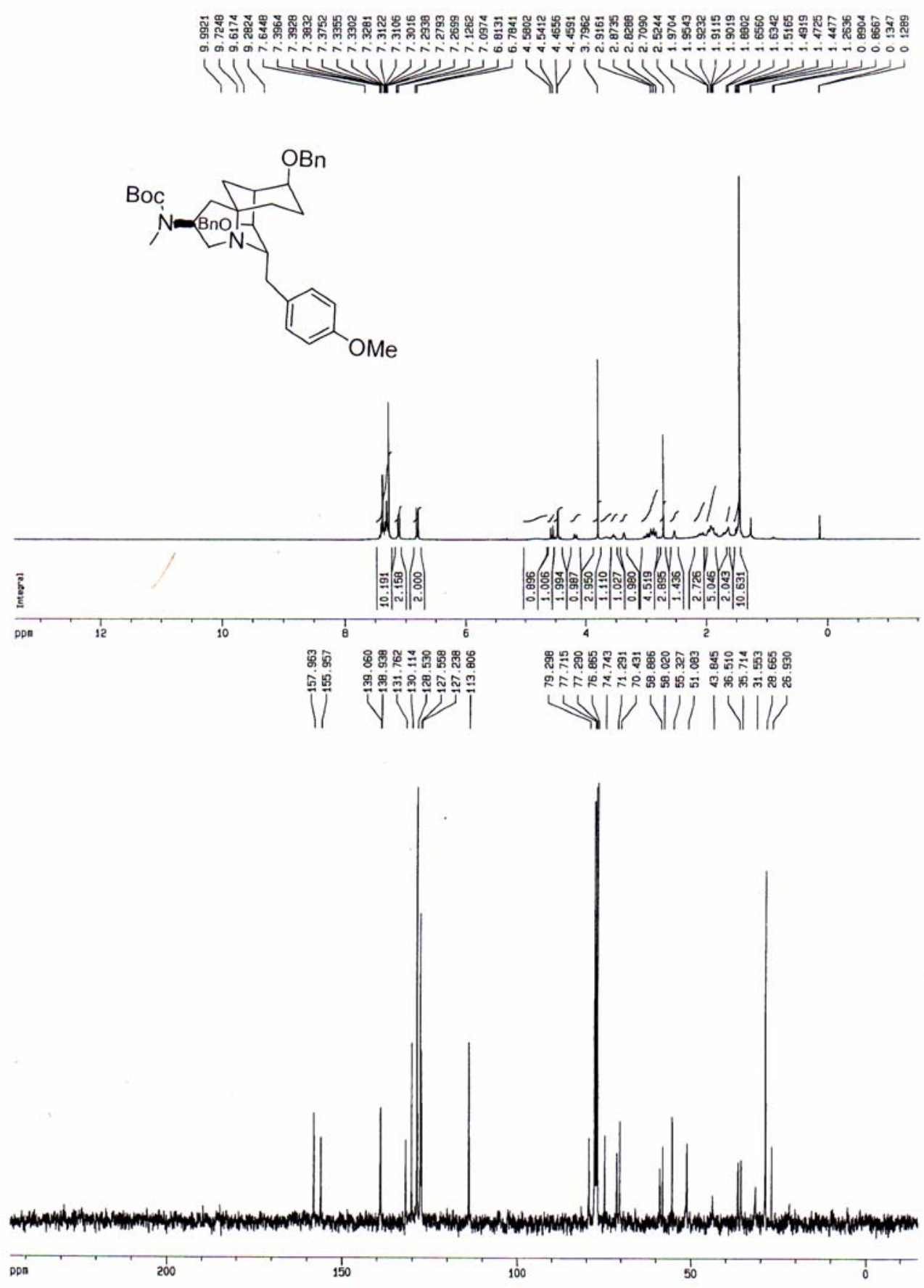


Compound $36 \beta$

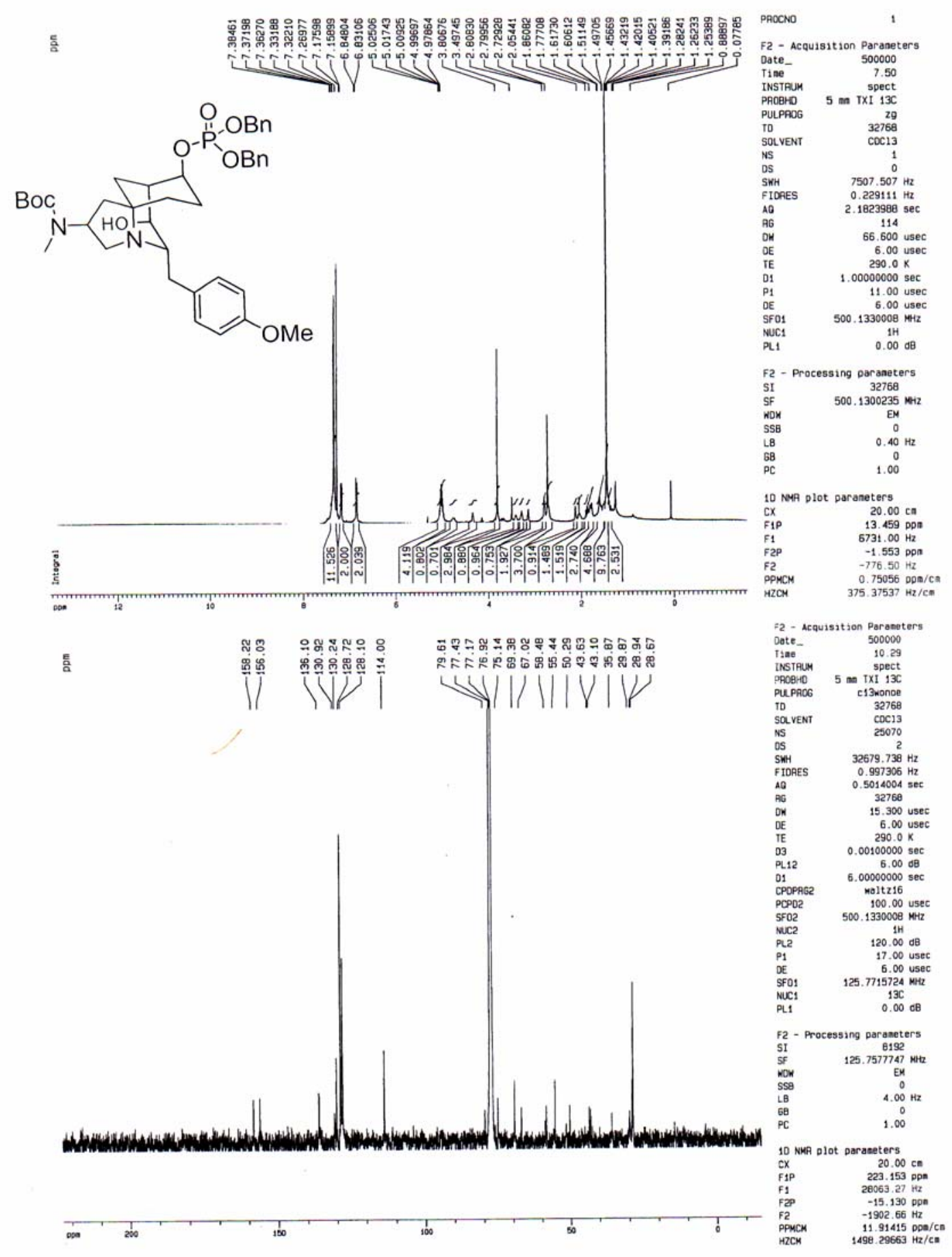




\section{Compound 24}

a
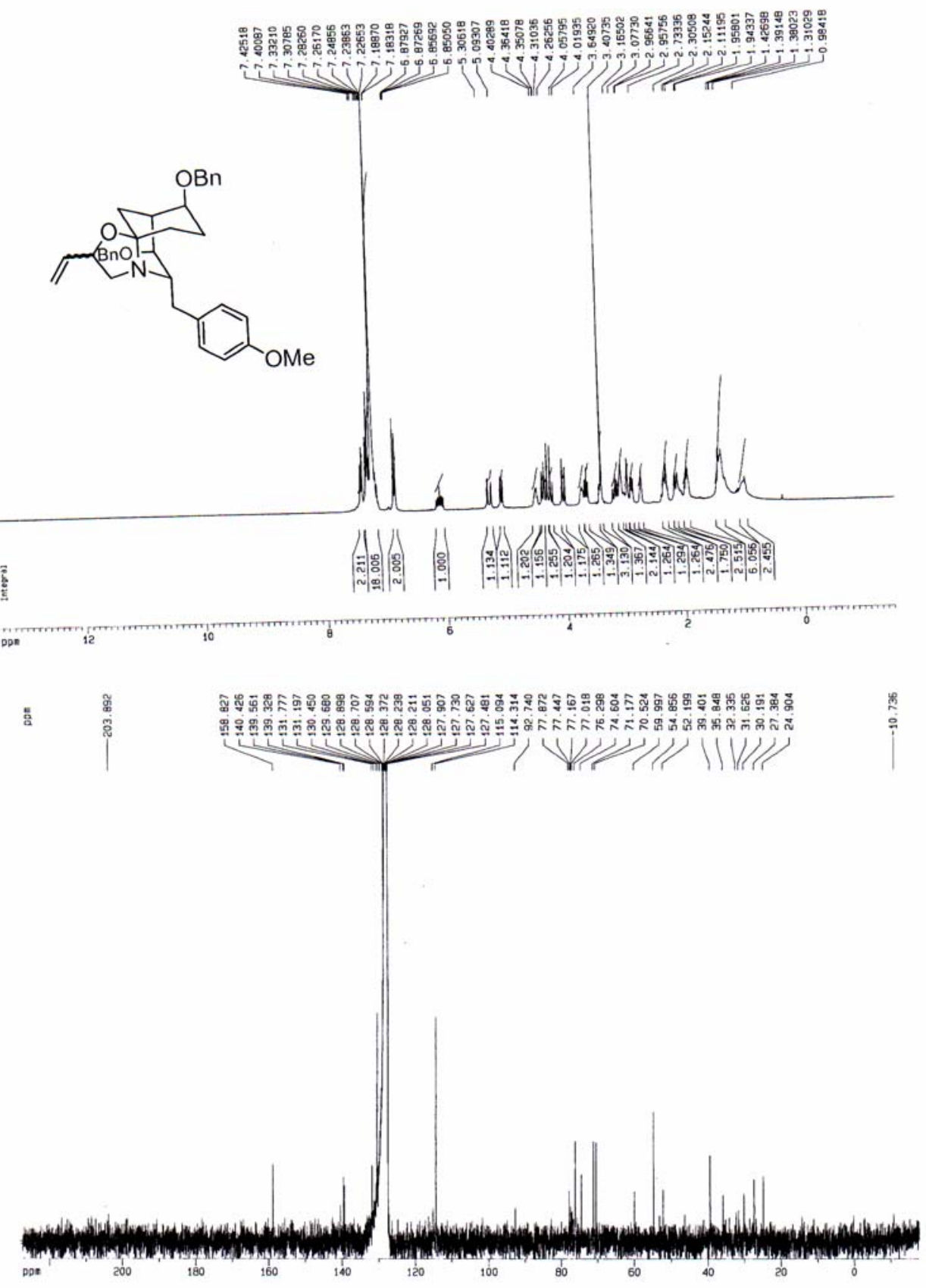
Compound 17
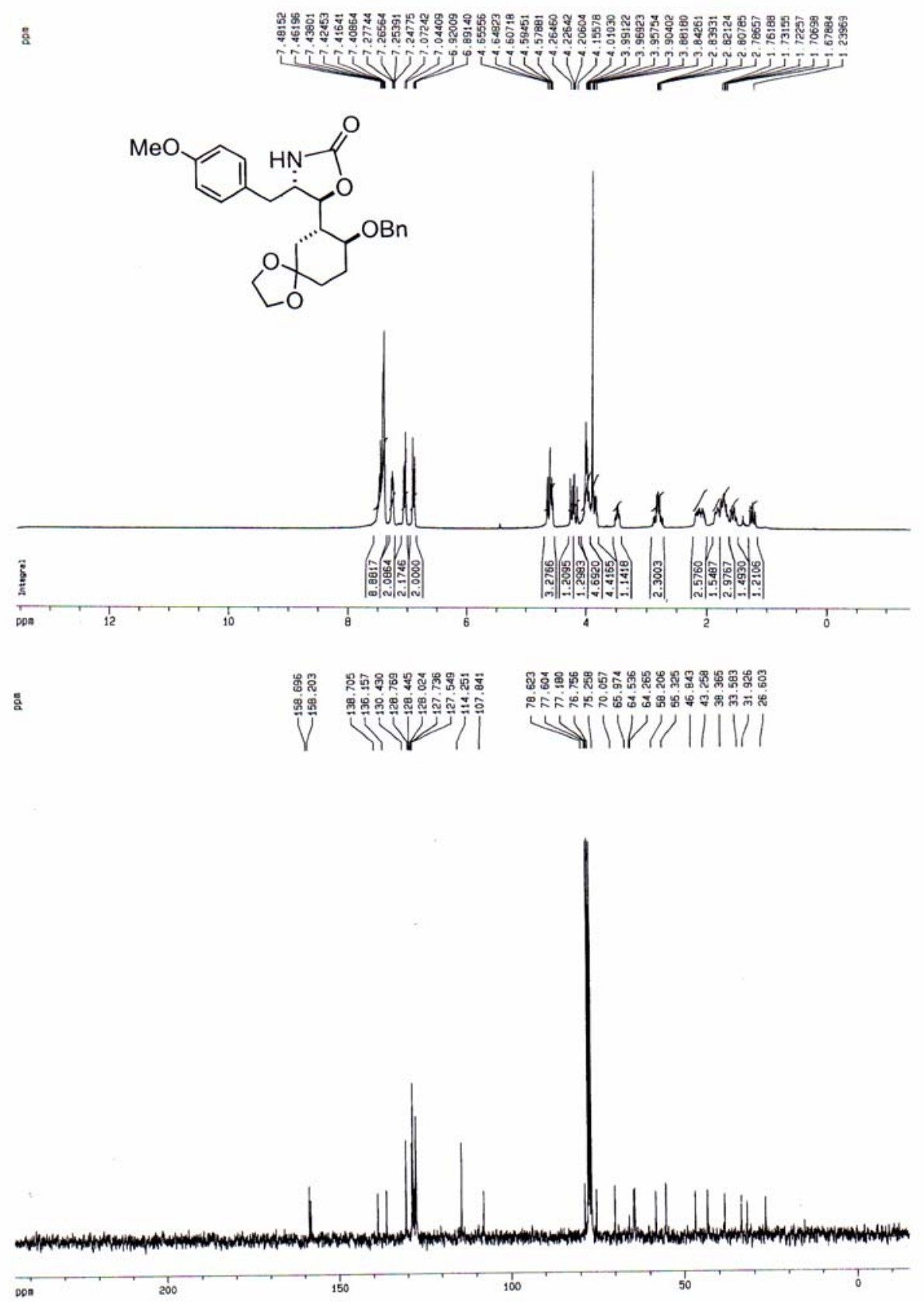
Compound 12

s.
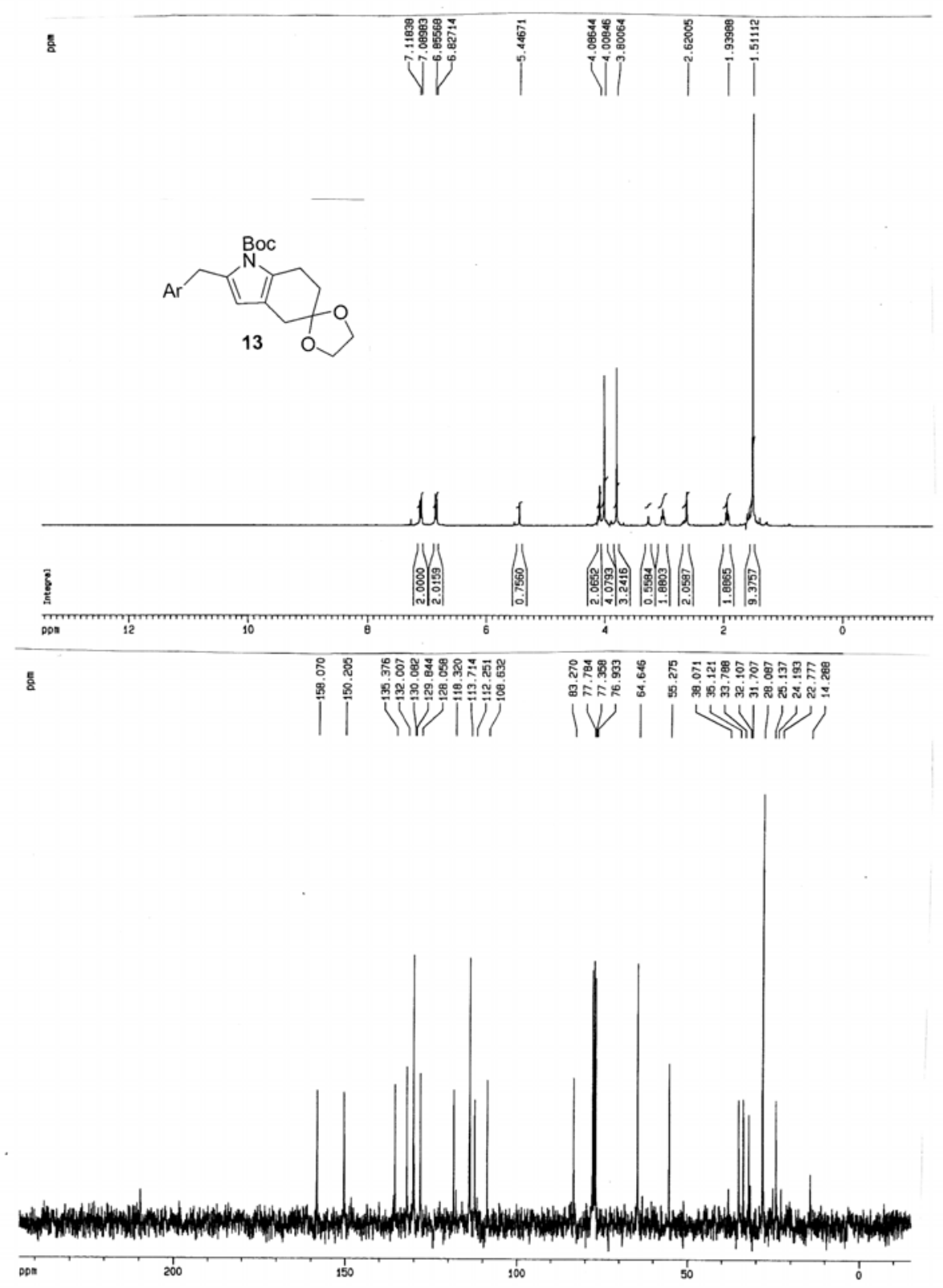
Crystal structures of Compound 11 and 26(isomer 1)

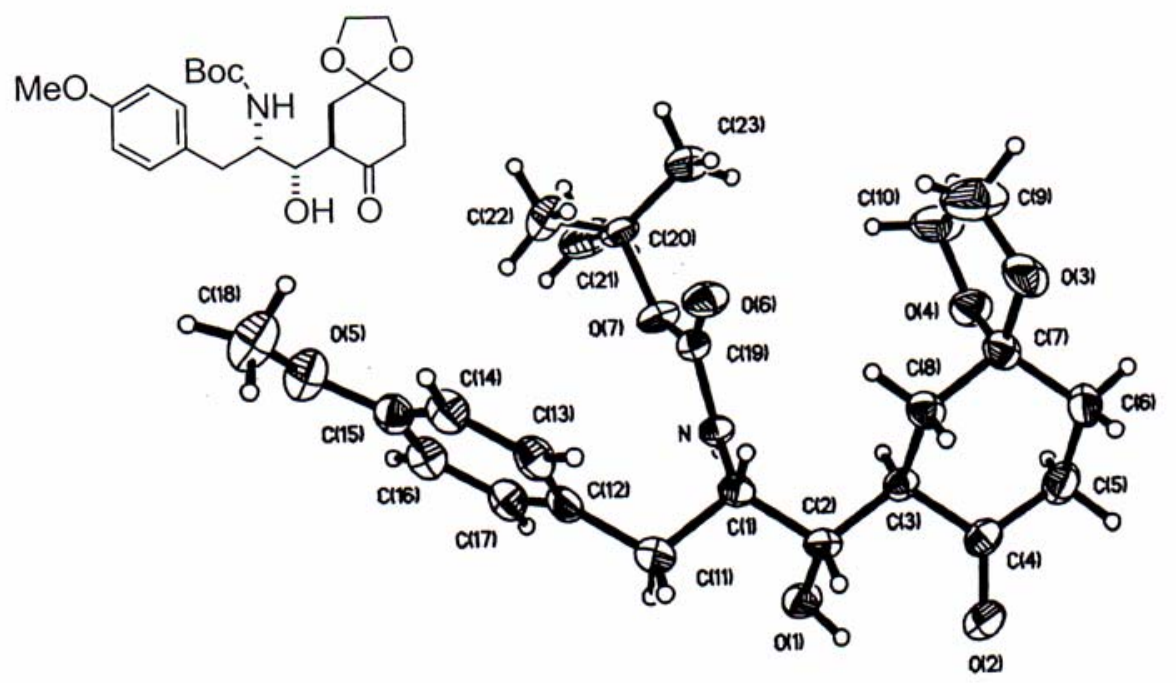<smiles>C=CC(OC)C(=O)N[C@H](Cc1ccc(OC)cc1)[C@H](OCc1ccccc1)[C@H]1CCC[C@@H](Cc2ccccc2)C12OCCO2</smiles>

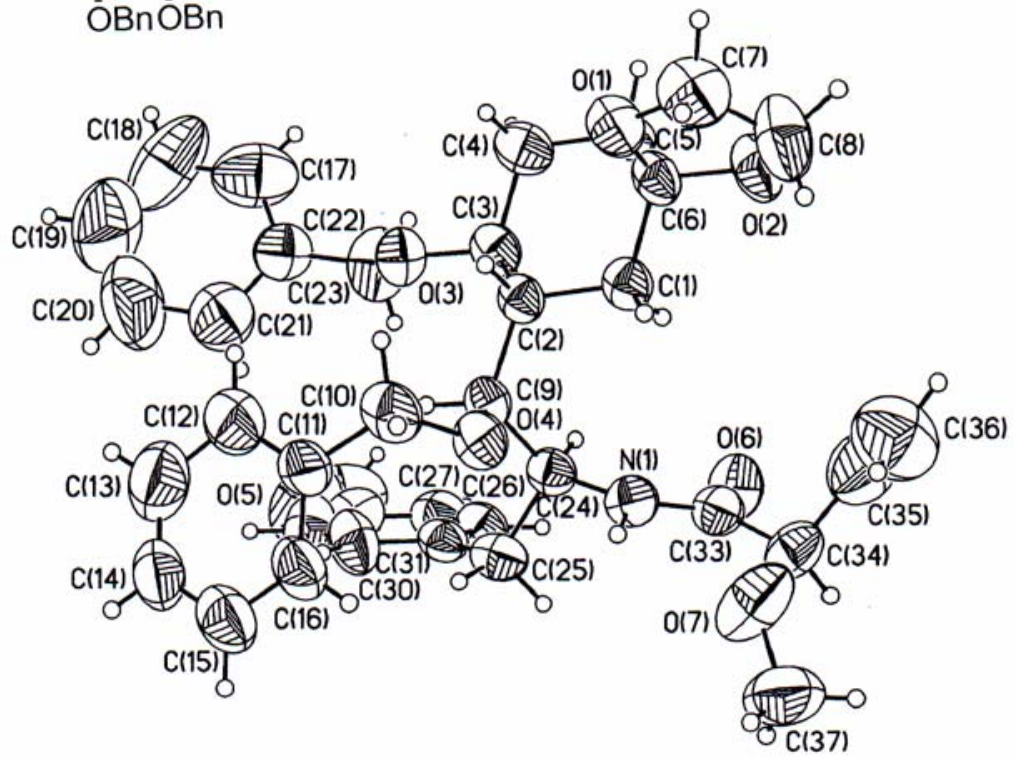

